International Journal of Social Science and Economic Research

ISSN: 2455-8834

Volume:05, Issue:12 "December 2020"

\title{
INFLATION GROWTH NEXUS IN WAEMU: A DYNAMIC PANEL THRESHOLD ANALYSIS
}

\author{
KOUSSERE Sotima Jocelyn \\ university of Abomey-Calavi, Benin
}

DOI: 10.46609/IJSSER.2020.v05i12.002 URL: https://doi.org/10.46609/IJSSER.2020.v05i12.002

\section{Introduction}

Keeping inflation low and stable is one of the ultimate objectives of all modern Central Banks. The adverse negative effects of high inflation are well known: welfare cost of the society, obstruction to the signaling role of relative price changes that leads to resource misallocation, greater deterioration of the purchasing power of the poor and more importantly, lower long-term economic growth. Because of all these reasons, low and stable inflation is considered as an integral part of Macroeconomic stability.

The monetary policy conducted by the Central Bank in West African Economic and Monetary Union (WAEMU) is based on an Exchange Rate Anchor framework, where the domestic currency is pegged to the euro. The main objective of monetary policy in the region has traditionally been the fight against high inflation, paramount for the preservation of the internal and external value of the domestic currency. The convergence criteria of the zone require that inflation rates should not exceed $3 \%$ in member countries and therefore, the Central Bank inflation target band is from 0 to $2 \%$. Thus, keeping inflation below $2 \%$ has always been the main target of the monetary policy of the Central Bank, making inflation relatively low and stable in the region for years. The literature suggests that in the long run, the relationship between inflation and growth is negative (Barro 1995, Fischer 1993), but evidence suggests that in the short term, at low level, a rising inflation can boost growth. Thus, being mindful of the growth harming effects of very high as well as very low rates of inflation (Ghosh and Phillips, 1998), the below question may be posed in the context of WAEMU economy: was the inflation rate targeted in WAEMU zone appropriate? In other words, was that inflation target optimal, that is, that maximizes economic growth? Results from some empirical studies like Khan and Senhadji (2001) have suggested that inflation threshold range is $1-3 \%$ for industrialized countries and 11-12\% for developing countries, while Kremer, Bick and Nautz (2009), found that the estimated inflation threshold is about $2.5 \%$ for industrialized countries and $17 \%$ for developing countries. Moreover, most studies support the idea that when the existence of the threshold, and 


\section{International Journal of Social Science and Economic Research}

ISSN: $2455-8834$

Volume:05, Issue:12 "December 2020"

consequently the non-linearity in the relationship between inflation and growth, is ignored, the estimation of that relationship could be biased.

The purpose of this study is to investigate the relationship between inflation and economic growth in WAEMU and to determine whether a threshold level of inflation, above which the inflation effect on economic growth switches from positive or insignificant to negative. The investigation has been carried out through a Dynamic Panel Threshold specification, which assumes that there is a level of inflation beyond which the relationship between inflation and growth changes. The approach has been used by Patillo, Poirson and Ricci (2002), Pollin and Zhu (2005), Khan and Senhadji (2001).

The remainder of this paper is organized as follows: section 2 provides a brief review of theoretical and empirical literature on the relationship between inflation and growth; section3 presents the methodological framework of this research and section 4 discusses the findings and policy implications of the study.

\section{Literature Review}

The literature contains a lot of theoretical and empirical studies dealing with the relationship between inflation and growth.

A theoretical model developed by Mundell (1965) and Tobin (1965) predicts a positive relationship between inflation and capital accumulation, which in turn implies a positive impact on growth. The so-called Mundell-Tobin effect states that since money and capital are substitutable, an increase in the inflation rate erodes the purchasing power of monetary assets, which causes substitution between resources and leads to a shift in the portfolio allocation away from monetary assets to real assets. In the same vein, Lucas (1973); Kiley (2000) argued that under wage and price rigidities, a certain level of inflation can help to realign the relative prices in response to structural changes in production during fast modernization periods of the economy. In the context, inflation is rather important for economic growth.

For developing countries, some studies pointed out that inflation contributes positively to economic growth as it induces savings and investment through numerous channels (Baer, 1967; Georgescu-Roegen, 1970). Governments in developing countries often resort to money creation to finance their budget deficits. This seignior age, of inflation tax resources, may be used by governments to increase capital formation by financing real investment. As long as this mechanism does have a crowding out effect on private investment, would contribute to economic growth.

A look at the empirical evidence on the inflation-growth nexus reveals that results vary across time depending on data periods, country experiences and research methodology. 


\section{International Journal of Social Science and Economic Research}

ISSN: $2455-8834$

Volume:05, Issue:12 "December 2020"

Mallik and Chowdhury (2001) examined the relationship between inflation and economic growth for Bangladesh, India, Pakistan and Sri Lanka. Unbalanced sample size was used for four countries in that study. They found evidence showing a positive relationship between inflation and economic growth rate in all four countries studied. The result indicates that while moderate inflation level supports economic growth, faster growth feedbacks into inflation. Thus, these countries are on a "knife-edge".

Khan and Senhadji (2001) explored where there existed a threshold effect in the relationship between inflation and growth in their study on 140 industrialized and developing countries in the period from 1960 to 1998 . They predicted the threshold to be 1 to $3 \%$ for industrialized countries and to be $7 \mathrm{t}$ o $11 \%$ for developing countries. They found out that inflation rates over these values negatively influenced economic growth whereas inflation rates under these values did not influence it. Gylfason and Herbertsson (2001) conducted a similar study on 170 countries for the period between 1960 and 1992, and determined that an inflation rate exceeding 10 to $20 \%$ on a yearly basis negatively affected economic growth.

Using panel data covering 1960-1996, Sarel (1996) estimates the threshold level of inflation in the 8-10 percent range. Below the threshold inflation rate, inflation has no significant effect on growth. For inflation rates greater than 8 percent, the effect is negative, and statistically significant. Ghosh and Phillips (1998), using a larger sample than Sarel, find a substantially lower threshold level of inflation, at an annual rate of $2 \frac{1}{2} 2$ percent.

Khan and Senhadji (2001) show that the inflation threshold tends to be higher in developing countries, with threshold estimates falling in the 7-11 percent range versus 1-3 percent for industrial countries. They also find the negative relationship between inflation and growth beyond the threshold level of inflation is quite robust to sample size, model specification, and the estimation method.

Barro (1995) explored the inflation-growth nexus using panel data for 100 countries over the period 1960-1990. His empirical finding was that there exists a statistically significant negative relationship between the two variables. He estimated that an average increase in inflation of $10 \%$ reduces output growth by $0.2 \%$ to $0.3 \%$. In a cross-country study with a data set covering the same period, Motely (1998) detected a similar relationship and his finding was that an increase in inflation of $5 \%$ results in a decrease of economic growth of $0.1 \%$ to $0.5 \%$.

Bruno and Easterly (1998) examined the determinants of economic growth using cross-sectional data from 26 countries for the period 1961-1992. They argued that the negative relationship between inflation and growth exists only in high frequency data and with extreme inflation observations. In their empirical analysis, they detected a threshold level of $40 \%$, above which the relationship between inflation and growth was negative. In addition, they found an inconclusive 
International Journal of Social Science and Economic Research

ISSN: 2455-8834

Volume:05, Issue:12 "December 2020"

relationship between inflation and economic growth below this threshold level when countries with high inflation crises were excluded from the sample.

Working with data of a panel from 124 industrialized and developing countries, Kremer, Bick and Nautz (2009) investigated the presence of threshold effects of inflation on long-term economic growth. Their empirical results showed that the estimated inflation threshold level was about $2.5 \%$ for industrialized countries and $17 \%$ for developing countries. Above these critical levels, the inflation rate leads to a lower long-term economic growth rate in both cases. In addition, the study indicated that below these thresholds, the effect of inflation on long-term economic growth was significantly positive in developed countries. By contrast, there was no significant impact on economic growth in developing countries when inflation was below $17 \%$.

\section{Methodology and Data}

In the current study, the relationship between inflation and economic growth was investigated for the period 1985-2009 for 7 WAEMU countries including Benin, Burkina-Faso, Cote-d'Ivoire, Mali, Niger Senegal and Togo. Guinea-Bissau is excluded from the study since the country has joint the union in 1997 and hence, its data is not available for the period of the study. The study is done using a dynamic panel data analysis which takes into account inflation threshold level.

The starting point of the investigation into the threshold effects on the inflation-growth nexus in WAEMU is a general model describing the link between economic growth and it determinants. The model used in this paper is inspired by the one used by drukker \& al (2005). We specify a general model establishing the link between economic growth and its determinants augmented with inflation in two regimes as follows:

$$
\begin{array}{ll}
Y_{i, t}=\mu_{i}+Y \pi_{i, t}+\sigma P O P_{i, t}+\rho \text { Topen }_{i, t}+\alpha F D I_{i, t}+\beta Y_{i, t-1}+\varepsilon_{i, t} & \text { if } \pi_{i, t} \leq \emptyset \\
Y_{i, t}=\mu_{i}+Y \pi_{i, t}+\sigma P O P_{i, t}+\rho \text { Topen }_{i, t}+\alpha F D I_{i, t}+\beta Y_{i, t-1}+\varepsilon_{i, t} & \text { if } \pi_{i, t}>\emptyset
\end{array}
$$

Where $\boldsymbol{Y}_{\boldsymbol{i}, \boldsymbol{t}}$ is the annual real GDP per capita, $\boldsymbol{\pi}_{\boldsymbol{i}, \boldsymbol{t}}$ represents the semi-log of inflation rate, POPstands for the population growth rate, Topenis trade openness calculated as the ratio of the sum of exports and imports to GDP, $\boldsymbol{F D I}$ represent Foreign Direct Investment flows, and $\boldsymbol{\varepsilon}_{\boldsymbol{i}, \boldsymbol{t}}$ is the error term and $\varnothing$ is the inflation threshold that is the level of inflation above which the inflation effect on economic growth switches from positive or insignificant to negative. The choice of explanatory variables including the population growth rate, trade openness and Foreign Direct Investment is based on the existing literature on the significant determinants of economic growth for the region. 
International Journal of Social Science and Economic Research

ISSN: 2455-8834

Volume:05, Issue:12 "December 2020"

The equations (1) and (2) present the two regimes of the effects of inflation on economic growth. In the equation (1), inflation is low, that is below the threshold and the relationship between inflation and growth is expected to be positive. In other words, in the first regime, higher inflation leads to higher GDP or to an insignificant effect.

In the equation (2), where inflation is above the threshold, its effect on economic growth is expected to be negative. In other words, above the threshold, higher inflation is detrimental to economic growth.

The explanatory variables used as growth determinants in this research has also been used in some influential empirical works investigating the relationship between inflation and growth (Sarel, 1996; Khan and Senhadji, 2001; and Kremer, Bick and Nautz, 2009) as well as in recent works on developing economies (Risso and Carrera, 2009; Frimpong and Oten-Abayie, 2010; Seleteng, Bittencourt and van Eyden, 2011; Ghazouani, 2012; Ayisi, 2013; Ahortor, Adenekan and Ohemeng, 2012).

The equations (1) and (2) can be combined through a redefinition of the variable $\boldsymbol{\pi}_{\boldsymbol{i}, \boldsymbol{t}}$ as follows:

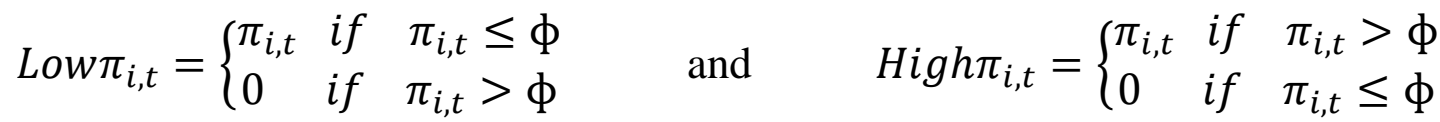

We obtain a unique equation showing the two regimes as follows:

$Y_{i, t}=\mu_{i}+\vartheta L o w \pi_{i, t}+\delta H i g h \pi_{i, t}+\sigma P O P_{i, t}+\rho \operatorname{Topen}_{i, t}+\alpha F D I_{i, t}+\beta Y_{i, t-1}+\varepsilon_{i, t}$

Where $\boldsymbol{\vartheta}$ and $\boldsymbol{\delta}$ are the marginal effects of inflation on economic growth and may be different depending on regimes.

Theoretically, the expected effects of the different explanatory variables on growth in Equation 3 are as follows:

The growth rate of the population (POP) may have either a positive or a negative effect on output growth. According to Todaro (1996), larger populations can stimulate economic growth through it effect on aggregate demand. Moreover, since human capital is an important component of production factors, it can positively affect economic growth. However, as Kelley (1988) pointed out, population growth could also have a negative impact on economic growth if the dependency of the young population lowers investment as a result of diverting resources from more productive activities to basic needs, or if the average productivity of physical capital is lowered via diminishing returns.

Regarding trade openness (Topen), theory and empirical studies have shown that trade does not have a simple and straightforward relationship with economic growth. In the context of 
International Journal of Social Science and Economic Research

ISSN: 2455-8834

Volume:05, Issue:12 "December 2020"

WAEMU countries, trade openness may be detrimental economic growth because of terms of trade shocks that often lead to unfavorable trade balances in these countries.

In its turn, Foreign Direct Investment (FDI) is expected to have a positive effect on economic growth in WAEMU. Several studies have shown that FDI facilitate trade, economic cooperation and improve business environment (Ndiaye and $\mathrm{Xu}, 2016$ ).

The data set used in this study include time series on per capita real GDP, population growth, inflation rate derived from the CPI, trade openness calculated as the ratio of the sum of exports and imports to GDP and Foreign Direct Investment. The set of data spanning 1985-2009 was collected from the World Bank Development Indicators.

\section{Findings and Policy implications}

The objective of the study was to empirically examine the relationship between inflation and economic growth in WAEMU, and to investigate the existence of possible threshold effects between these two variables. To this end, a dynamic panel threshold regression model using annual time series spanning 1980-2009 has been used to estimate the threshold level of inflation. The below tables report the results of estimating Equation (3) using inflation rate as a threshold variable.

Threshold Estimator (Level = 95)

\begin{tabular}{l|lll}
\hline Model & Threshold & Lower & Upper \\
\hline Th & 11.30 & 10.611512 .2937 & \\
\end{tabular}

Threshold effect test $($ Bootstrap $=300)$

\begin{tabular}{|c|c|c|c|}
\hline Threshold & RSSMSEFstat & Crit10 & Crit5Crit1 \\
\hline Single & 0.0000 & -150.001 .0000 & 391.2636603 .2045752 .8406 \\
\hline
\end{tabular}

Fixed-effects (within) regression

$\begin{array}{llr}\text { Number of obs } & = & 175 \\ \text { Number of groups } & = & 7 \\ \text { F(6, 162) } & = & 1329.63 \\ \text { Prob }>\text { F } & = & 0.0000\end{array}$

Group variable: $\mathrm{i}$

R-sq: Within $=0.9801$

Between $=0.9994$ 
International Journal of Social Science and Economic Research

ISSN: 2455-8834

Volume:05, Issue:12 "December 2020"

Overall $=0.9929$

Corr $\left(u \_i, X b\right)=0.0374$

\begin{tabular}{|c|c|c|c|c|}
\hline \multirow{2}{*}{$\begin{array}{l}\mathrm{Y} \\
\pi\end{array}$} & \multirow{2}{*}{$\begin{array}{l}\text { Coef. } \quad P>|t| \\
-.791630 .02569\end{array}$} & \multicolumn{3}{|c|}{ 95\% Conf. Interval] } \\
\hline & & -1.2365 & -0.024586 & \\
\hline Topen & -376.54 & 0.00054 & -539.32 & -213.7525 \\
\hline $\mathrm{Y}(\mathrm{t}-1)$ & 0.09842 & 0.00000 & 0.00089 & 0.2305645 \\
\hline FDI & $1.25 \mathrm{e}-07$ & 0.00008 & $4.08 \mathrm{e}-8$ & $2.09 \mathrm{e}-7$ \\
\hline Pop & 2.41 & 0.19856 & -17.66 & 22.495 \\
\hline \multicolumn{5}{|c|}{ _Cat\#C. Y } \\
\hline 0 & 3.36 & 0.00078 & 0.8 & 5.9 \\
\hline 1 & -4.53 & 0.02649 & -6.8 & -2.1 \\
\hline \multirow[t]{2}{*}{ _Cons } & 38.5698 & 0.00058 & 12.0325 & 75.2638 \\
\hline & Prob>F & & & \\
\hline
\end{tabular}

The upper part of the tables shows the estimated inflation threshold level and the corresponding 95\% confidence interval. As shown in the table, estimated optimal threshold value for inflation is found to be $11.30 \%$ with the confidence interval [10.6115 - 1202937]. The middle part of the table reports a robustness test for the threshold regression. The lower part shows the effect of inflation on economic growth for both regimes' types. The regime-dependent coefficients are statistically significant ( $\widehat{\boldsymbol{\vartheta}}=3.36$ and $\widehat{\boldsymbol{\delta}}=\mathbf{- 4 . 5 3}$ ), this means that inflation has a positive marginal effect on economic growth in the low inflation regime, whereas it has a negative marginal effect in the high inflation regime. The estimated coefficients of Foreign Direct Investment (FDI), and Trade openness (Topen) are statistically significant. FDI slightly boots economic growth while Topen at its current state in WAEMU, hurts economic growth. The population growth rate (Pop) has a positive coefficient, however, it is an insignificant 


\section{International Journal of Social Science and Economic Research}

ISSN: $2455-8834$

Volume:05, Issue:12 "December 2020"

determinant of economic growth. This is consistent with the range indicated in the related literature. For instance, Khan and Senhadji (2001), studying 110 developing countries, find the optimal threshold level of inflation rate to be equal to $11 \%$, whereas Kremer et al. (2013),studying 101 non-industrialized countries, report the threshold to be $17.2 \%$. In developing economies, Baglan and Yoldas (2014) determine the optimal threshold level of inflation rate as 12\%, while Das and Loxley (2013) report a threshold of $11 \%$.

The analysis of this paper has important policy implications. First, the findings of the study revealed a significant difference between the inflation target used for policy objectives in WAEMU and the estimated inflation threshold. Since the Central Bank has been targeting an inflation level of around 3\% in the implementation of economic stabilization and structural adjustment programs, one could infer in light of this study that monetary and fiscal policies applied in these programs were tighter than necessary and that there was room for higher economic growth with a higher inflation rate without pushing the economy into an inflationary spiral.

Second, price stability being the primary objective of monetary policy conducted by the Central Bank in WAEMU, the monetary authorities should also be mindful of the trade-off between inflation, growth and employment in WAEMU composed of developing countries accounting among the poorest countries in the world, where supply shocks are prominent.

Finally, this paper suggests that the upper limit of the inflation target for policy objectives in WAEMU should be $11.30 \%$, rather than $3 \%$. This implies that more relaxed monetary policy should be pursued when inflation is lower than $11.30 \%$, while a tighter stance should be adopted when the inflation rate approaches $11.30 \%$.

\section{References}

Ahortor, C.R.K., A. Adenekan and W. Ohemeng. 2012. "An estimate of inflation threshold in the WAMZ: The case for Ghana and Nigeria". Journal of Monetary and Economic Integration, 11:158-201.

Ayisi, R. 2013. "Single digit inflation and economic growth". American Journal of Economics and Business Administration, 5: 22-28.

Baer, W. 1967. "The inflation controversy in Latin America: A survey". Latin AmericanResearch Review, 2: 3-25.

Baglan, D. and Yoldas, E., 2014. Non-linearity in The Inflation-Growth Relationship inDeveloping Economies: Evidence from A Semiparametric Panel Model.EconomicsLetters, 125(1), pp.93-96. 
International Journal of Social Science and Economic Research

ISSN: 2455-8834

Volume:05, Issue:12 "December 2020"

Barro, R.J., 1995. Inflation and Economic Growth. NBER Working Paper Series, No. 5326, National Bureau of Economic Research.

Bruno, M. and W. Easterly. 1998. "Inflation crises and long-run growth". Journal of Monetary Economics, 41: 3-26.

Das, A. and Loxley, J., 2015. "Non-linear Relationship Between Inflation and Growth in Developing Countries."Economic \& Political Weekly, 50(37), pp.59-64.

Drukker, D. Gomis-Porqueras, P. and Hernandez-Verme, P., 2005. "Threshold Effects in The Relationship between Inflation and Growth: A New Panel-Data Approach."MPRA Working Paper Series, No. 38225.

Fischer, S., 1993. "Inflation and Growth. NBER Working Paper Series, No: 1235", National Bureau of Economic Research.

Frimpong, J.M. and E.F. Oteng-Abayie. 2010. "When is inflation harmful? Estimating the threshold effect for Ghana". American Journal of Economics and Business Administration, 2: 225-232.

Georgescu-Roegen, N. 1970. "Structural inflation-lock and balanced growth". Economies et Societes, 4: 557-605.

Ghazouani, S. 2012. "Threshold effect of inflation on growth: evidence from MENA region". Working Paper No. 715. Economic Research Forum.

Ghosh, A. and Phillips, S., 1998. "Warning: Inflation May Be Harmful to Your Growth", IMF Staff Papers, 45(4), pp.672-710.

Kelley, A.C. 1988. "Population pressures, savings and investment in the Third World: Some puzzles". Economic Development and Cultural Change, 36: 449-64.

Khan, M.S. and Senhadji, A.S., 2001. "Threshold Effects in The Relationship between Inflation and Growth". IMF Staff Papers, 48(1), pp.1-21.

Kiley, M. 2000. "Endogenous price stickiness and business cycle persistence". Journal of Money, Credit and Banking, 32: 28-53.

Kremer, S. Bick A. and Nautz D., 2013. "Inflation and Growth: New Evidence from A Dynamic Panel Threshold Analysis". Empirical Economics, 44(2), pp.861-878.

Lucas, R.E. 1973. "Some international evidence on output-inflation trade-offs". American Economic Review, 63: 326-34. 
International Journal of Social Science and Economic Research

ISSN: 2455-8834

Volume:05, Issue:12 "December 2020"

Mallik, G. and Chowdhury A., 2001. "Inflation and Economic Growth: Evidence from Four South Asian Countries". Asia-Pasific Development Journal, 8 (1), pp.123-135.

Motely, B. 1998. "Growth and inflation: A cross-country study". Federal Reserve Bank of San Francisco Economic Review, 1: 15-28.

Mundell, R. 1965. "Growth, stability and inflationary finance". Journal of Political Economy, 73: $97-109$.

Pattillo, C., Poirson and R.A. Ricci. 2002. "External debt and growth". IMF Working Paper 02/69. International Monetary Fund, Washington.

Pollin, R. and A. Zhu. 2005. "Inflation and economic growth: A cross-country non-linear analysis". Working Paper Series No. 109. PERI, University of Massachusetts Amherst.

Risso, W.A. and E.J. Carrera. 2009. "Inflation and Mexican economic growth: Long-run relation and threshold effects". Journal of Financial Economic Policy, 1: 246-263.

Sarel, M. 1996. "Non-linear Effects of Inflation on Economic Growth". IMF Staff Papers, 43: 199-215. International Monetary Fund, Washington.

Seleteng, M., M. Bittencourt and R. van Eyden. 2011. "Non-linearities in inflation-growth nexus in the SADC Region: A panel smooth transition regression approach". Working Paper /2011/26. University of Pretoria, Pretoria.

Tobin, J. 1965. “Money and economic growth”. Econometrica, 33: 671-684. 